\title{
Lupus nephritis in pregnancy; a mini-review to current knowledge
}

\author{
Karim Mowla ${ }^{1}$, Maryam Alwanian² ${ }^{2}$ Sara Bahadoram ${ }^{3}$, Mohammad Bahadoram $^{2 *}$ \\ ${ }^{1}$ Department of Rheumatology, Golestan Hospital, Ahvaz Jundishapur University of Medical Sciences, Ahvaz, Iran \\ ${ }^{2}$ Medical Student Research Committee \& Social Determinant of Health Research center, Ahvaz Jundishapur University of Medical Sciences, \\ Ahvaz, Iran \\ ${ }^{3}$ Department of Pediatrics, Imam Khomeini Hospital Complex, Tehran University of Medical Sciences, Tehran, Iran
}

\section{A R T I C L E IN F O}

Article Type:

Mini-Review

\section{Article History:}

Received: 10 July 2017

Accepted: 19 November 2017

Published online: 6 December 2017

\begin{abstract}
Systemic lupus erythematosus (SLE) is an auto-immune disease with the highest incidence in women of reproductive age. Recent studies indicate an increased rate of lupus flare during pregnancy. One main cause of death in lupus patients is renal involvement that is manifested as lupus nephritis. Active lupus nephritis is the biggest threat to pregnancy outcome in women with lupus. Consultation with a nephrologist, rheumatologist and perinatologist is recommended in order to carry a successful pregnancy to term.
\end{abstract}

Keywords:

Lupus nephritis

Systemic lupus erythematosus

Pregnancy

\begin{abstract}
Implication for health policy/practice/research/medical education:
Recent studies indicated that high incidence of lupus occurs in women of childbearing age. Lupus and pregnancy have undesired reciprocal effects on one another. Lupus nephritis is one of the most hazardous manifestations of SLE during pregnancy. A tight control for these patients should be performed before, during, and after pregnancy.

Please cite this paper as: Mowla K, Alwanian M, Bahadoram S, Bahadoram M. Lupus nephritis in pregnancy; a mini-review to current knowledge. J Renal Inj Prev. 2018;7(1):42-44. DOI: 10.15171/jrip.2018.10.
\end{abstract}

\section{Introduction}

Systemic lupus erythematosus (SLE) is an autoimmune disease that affects various organs. The highest prevalence is in women of reproductive age. In the United States, about 4,500 pregnancies per year occur in women with SLE (1). Lupus exacerbation in pregnancy can be observed in more than $50 \%$ of cases. In this mini-review we sought to review the recent investigations regarding lupus nephritis.

The flare of the disease occurs alike throughout the pregnancy and often occurs immediately after the termination of pregnancy (2). Changes in sex hormones during pregnancy affect the immune system and can cause SLE flaring (3). The immune cells and lymphatic tissues have receptors for sex hormones and the hormonal system has also receptors for cytokines. In pregnancy, serum levels of gonadotropins and sex steroids including luteinizing hormone and follicular stimulatory hormones, estrogen, and progesterone are different in people with SLE than in healthy ones $(4,5)$. Within pregnancy in people with SLE, a decrease in serum concentrations of estradiol, cortisol, testosterone, and dehydroepiandrosterone sulfate and progesterone was reported in comparison with the control group (6). Some studies have identified the role of estrogen in the development of the disease. Estrogen can stimulate the maturation of peripheral immune cells, especially $\mathrm{T}$ cells. These cells contribute to promoting the immune system tolerance as well as the immune system suppression. In a normal pregnancy, the number of $\mathrm{T}$ cells may increase in order to enhance the fetal tolerance, but in patients with lupus, a decrease in the function of $\mathrm{T}$ cells has been observed, which can lead to poor prognosis in mothers with lupus (7-9).

\section{Materials and Methods}

For this mini-review, we used a variety of sources including PubMed, Embase, Scopus and directory of open access 
journals (DOAJ). The search was performed by using combinations of the following key words and or their equivalents; lupus nephritis, systemic lupus erythematosus, glomerular filtration rate, premature infants, anti- dsDNA antibody, Renal involvement, anti-phospholipid antibody, kidney disease, renal failure, proteinuria, poor fetal outcome and pregnancy.

\section{Renal involvement}

One of the most important causes of death in patients with lupus in the first decade is renal involvement. This defect is predominantly evidenced as lupus nephritis during pregnancy. The rate of active lupus nephritis in pregnancy is $4 \%$ to $30 \%$, and in a person with a history of the previous recurrence of lupus nephritis is estimated to be $20 \%$ to $30 \%$ (10). However, there are rare reports of lupus nephritis as the first manifestation of disease in pregnancy (11). The active lupus nephritis is the biggest threat to the outcome of pregnancy in women with lupus. The range of abortion rates in patients with a history of SLE before pregnancy was $36-8 \%$ that reaches $52 \%$ in women who have active lupus nephritis during pregnancy. Most disease attacks in pregnant women were mild to moderate in severity, and severe attacks were only reported in $10 \%$ to $40 \%$ of patients. Most of the reported attacks involve blood, musculoskeletal and renal systems. In women with moderate to good disease control, the number of attacks is less. Disease-related attacks in mothers seem to be more related to the problems of premature infants. Studies have shown that active nephritis can be an independent factor in increasing fetal mortality. Disease activity six months before pregnancy is a prognostic factor for the development of lupus nephritis $(12,13)$.

Physiologically, pregnancy increases glomerular filtration rate and increases blood volume, causing stress on the kidney system (1). These conditions in people with underlying kidney disease can cause further kidney damage (14). During normal pregnancy, glomerular filtration rate can increase by $50 \%$ and creatinine clearance by $30 \%$. Creatinine levels ranged from 0.4 to $0.6 \mathrm{mg} / \mathrm{dL}$ is considered normal in a pregnancy and the value higher than $0.8 \mathrm{mg} / \mathrm{dl}$ is considered to be elevated.

Significant renal failure before pregnancy has been associated with poor fetal outcome and the likelihood of early delivery is higher in women whose proteinuria is in the nephrotic range. Serum creatinine higher than $140 \mathrm{mmol} / \mathrm{L}$ has been associated with a $50 \%$ chance of losing pregnancy and if the creatinine level exceeds 400 $\mathrm{mmol} / \mathrm{L}$, this probability increases up to $80 \%$. Women with nephrotic syndrome are at increased risk for thrombosis and therefore, treatment with low doses of aspirin during pregnancy should be done regardless of the level of antiphospholipid antibodies.

\section{Diagnostic laboratory tests}

The level of anti-dsDNA antibody is associated with SLE (2). Women with a history of kidney disease, in addition to serially measuring serum creatinine, dsDNA and complementary levels $(\mathrm{C} 3, \mathrm{C} 4)$ should be tested planned for 24-hour urine collection to measure creatinine clearance and proteinuria at least once a month. If proteinuria is detected in the urine analysis, urine samples should be sent for microscopic examination to detect glomerular red blood cells or RBC casts that are prognostic factors for active renal disease. A kidney biopsy should be conducted in any patient with lupus that has clinical or laboratory evidence of active nephritis (2). Immunosuppressive therapy in mothers with lupus is administered in two phases; as an induction therapy at the start of the diagnosis or during an attack phase and in the recovery phase as preservative treatment.

\section{Treatment}

The goal of lupus treatment is to normalize renal function or at least to prevent progression of renal dysfunction (15). Precise follow up of pregnant women with lupus, treatment of complications and also prevention of teratogenic side effects is important. Due to the teratogenicity of a wide range of immunosuppressive drugs including cyclophosphamide and mycophenolate mofetil, treatment for lupus nephritis is restricted. Selective treatment of the disease in pregnancy include corticosteroids and azathioprine are suitable modalities (16).

Patients with lupus nephritis, especially hypertensive patients and antiphospholipid syndrome, are susceptible to preeclampsia if they will be pregnant (17). The risk of preeclampsia in patients with lupus is between $10 \%$ and $35 \%$ and in women with creatinine levels above $2.8 \mathrm{mg} / \mathrm{dL}$, the risk of preeclampsia and loss of pregnancy increases dramatically (18). In women with underlying kidney disease, the blood pressure should be controlled in a range lower than 140/90 mm Hg (19). The proposed drugs for pregnancy include methyldopa, nifedipine, diuretics, labetalol and hydralazine (20). Due to the possibility of embryonic anomalies, angiotensin-converting enzyme (ACE) inhibitors and angiotensin-receptor blockers (ARBs), should be avoided. Additionally, the administration of atenolol due to the possibility of an intrauterine growth retardation of the fetus should be avoided. Likewise, administration of spironolactone due to the anti-androgens property should be avoided (21). Additionally, in the case of anti-phospholipid antibody syndrome, anti-coagulants is necessary. Additionally in women with nephrotic range proteinuria, anti-coagulants should be prescribed due to increased coagulability. Aspirin should be prescribed to prevent preeclampsia. The administration of aspirin in mothers with lupus causes a better prognosis for fetus, for example it may reduce the incidence of abortion (22). Good pregnancy prognosis can be predicted in pregnant women with lupus in the complete remission period. To achieve a successful pregnancy, pre-pregnancy counseling is required. The incidence of abortion, preterm labor and perinatal adverse events in people with lupus are higher than that of healthy women.

\section{Conclusion}

Thus, all pregnancies in patients with lupus should be considered as high risk and should be performed 
in coordination with a gynecologist, perinatologist, rheumatologist and nephrologist. Several factors have been identified as the responsible for the loss of the fetus in lupus condition, but in the recent multivariate analysis, renal involvement has been revealed as the most important predictor. Anti-phospholipid antibodies (APA) test positivity can indicate the increased risk for poor prognosis. It seems that complete control of the patient's condition before fertilization such as being in complete remission at the beginning of pregnancy, lack of hypertension or renal failure, APA negativity and use of anticoagulant drugs can greatly improve the outcome of pregnancy.

\section{Authors' contribution}

All authors passed four criteria for authorship contribution based on recommendations of the International Committee of Medical Journal Editors. SB and MA searched and gathered the papers. $\mathrm{MB}$ prepared the primary draft. KM edited the manuscript and conducted the final revision and all authors read, revised, and approved the final manuscript.

\section{Conflicts of interest}

There were no points of conflicts to declare.

\section{Ethical considerations}

Ethical issues (including plagiarism, data fabrication, double publication) have been completely observed by the authors.

\section{Funding/Support}

Financial support was provided by Ahvaz Jundishapur University of Medical Sciences, Ahvaz, Iran.

\section{References}

1. Jaryal A, Vikrant S. Current status of lupus nephritis. Indian J Med Res. 2017;145:167-178. doi: 10.4103/ijmr. IJMR_163_16.

2. Bramham K, Soh MC, Nelson-Piercy C. Pregnancy and renal outcomes in lupus nephritis: an update and guide to management. Lupus. 2012;21(12):1271-83.

3. Zen M, Ghirardello A, Iaccarino L, Tonon M, Campana $\mathrm{C}$, Arienti S, et al. Hormones, immune response, and pregnancy in healthy women and SLE patients. Swiss Med Wkly. 2010;140:187-201.

4. Shabanova SS, Ananieva LP, Alekberova ZS, Guzov II. Ovarian function and disease activity in patients with systemic lupus erythematosus. Clin Exp Rheumatol. 2008; 26:436-41.

5. Doria A, Cutolo M, Ghirardello A, Zampieri S, Vescovi F, Sulli A, et al. Steroid hormones and disease activity during pregnancy in systemic lupus erythematosus. Arthritis Rheum. 2002;47:202-9.

6. Jara-Quezada L, Graef A, Lavalle C. Prolactin and gonadal hormones during pregnancy in systemic lupus erythematosus. J Rheumatol. 1991;18:349-53.

7. Aluvihare VR, Kallikourdis M, Betz AG. Regulatory T cells mediate maternal tolerance to the fetus. Nat Immunol. 2004;5:266-71.

8. Valencia X, Yarboro C, Illei G, Lipsky PE. Deficient CD4 pCD25high $T$ regulatory cell function in patients with active systemic lupus erythematosus. J Immunol. 2007;178: 257988.

9. Lyssuk EY, Torgashina AV, Soloviev SK, Nassonov EL, Bykovskaia SN. Reduced number and function of CD4 pCD25highFoxP3 $\mathrm{p}$ regulatory $\mathrm{T}$ cells in patients with systemic lupus erythematosus. Adv Exp Med Biol. 2007;601:113-9.

10. Clowse ME. Lupus activity in pregnancy. Rheum Dis Clin North Am. 2007;33:237-52.v

11. Miyamoto T, Hoshino T, Hayashi N, Oyama R, Okunomiya A, Kitamura S, et al. Preeclampsia as a Manifestation of NewOnset Systemic Lupus Erythematosus during Pregnancy. A Case-Based Literature Review. AJP Rep. 2016; 6:e62-7. doi: 10.1055/s-0035-1566245.

12. Kwok LW, Tam LS, Zhu T, Leung YY, Li E. Predictors of maternal and fetal outcomes in pregnancies of patients with systemic lupus erythematosus. Lupus. 2011;20:829-36.

13. Bertsias GK, Tektonidou M, Amoura Z, Aringer M, Bajema I, Berden JH, et al. Joint European League Against Rheumatism and European Renal Association-European Dialysis and Transplant Association (EULAR/ERA-EDTA) recommendations for the management of adult and paediatric lupus nephritis. Ann Rheum Dis. 2012;71:177182.

14. Smith MC, Moran P, Ward MK, Davison JM. Assessment of glomerular filtration rate during pregnancy using the MDRD formula. BJOG. 2008;115:109-12.

15. Ku M, Guo S, Shang W, Li Q, Zeng R, Han M, et al. Pregnancy outcomes in chinese patients with systemic lupus erythematosus (SLE): a retrospective study of 109 pregnancies. PLoS One. 2016;11:e0159364. doi: 10.1371/ journal.pone.0159364.

16. Bramham K, Lightstone L. Pre-pregnancy counseling for women with chronic kidney disease. J Nephrol. 2012;25:4509.

17. Bramham K, Hunt BJ, Bewley S, Germain S, Calatayud I, Khamashta MA, et al. Pregnancy outcomes in systemic lupus erythematosus with and without previous nephritis. J Rheumatol. 2011;38:1906-13.

18. Bandoli G, Palmsten K, Forbess Smith CJ, Chambers CD. A review of systemic corticosteroid use in pregnancy and the risk of select pregnancy and birth outcomes. Rheum Dis Clin North Am. 2017;43:489-502. doi: 10.1016/j.rdc.2017.04.013.

19. Berry C, Atta MG. Hypertensive disorders in pregnancy. World J Nephrol. 2016;5:418-28. doi: 10.5527/wjn.v5.i5.418.

20. Kattah AG, Garovic VD. The management of hypertension in pregnancy. Adv Chronic Kidney Dis. 2013;20:229-39.

21. Lateef A, Petri M. Systemic Lupus Erythematosus and Pregnancy. Rheum Dis Clin North Am. 2017;43(2):215-226. doi: $10.1016 /$ j.rdc.2016.12.009.

22. Hypertension in pregnancy. Report of the American College of Obstetricians and Gynecologists' Task Force on Hypertension in Pregnancy. Obstet Gynecol. 2013;122:112231.

Copyright $\odot 2018$ The Author(s); Published by Nickan Research Institute. This is an open-access article distributed under the terms of the Creative Commons Attribution License (http://creativecommons.org/licenses/by/4.0), which permits unrestricted use, distribution, and reproduction in any medium, provided the original work is properly cited. 